\title{
Mitochondrial Respiration in Intact Peripheral Blood Mononuclear Cells and Sirtuin 3 Activity in Patients with Movement Disorders
}

\author{
Slawomir Michalak, ${ }^{1}$ Jolanta Florczak-Wyspiańska, ${ }^{2}$ Joanna Rybacka-Mossakowska, ${ }^{1}$ \\ Wojciech Ambrosius, ${ }^{2}$ Krystyna Osztynowicz, ${ }^{1}$ Aleksandra Baszczuk, ${ }^{3}$ \\ Wojciech Kozubski, ${ }^{2}$ and Ewa Wysocka ${ }^{3}$

\begin{abstract}
${ }^{1}$ Department of Neurochemistry and Neuropathology, Poznan University of Medical Sciences, Przybyszewskiego str. 49, 60-355 Poznan, Poland

${ }^{2}$ Department of Neurology, Poznan University of Medical Sciences, Przybyszewskiego str. 49, 60-355 Poznan, Poland

${ }^{3}$ Chair and Department of Laboratory Diagnostics, Poznan University of Medical Sciences, Szamarzewskiego str. 82/84,
\end{abstract} \\ 60-569 Poznan, Poland
}

Correspondence should be addressed to Slawomir Michalak; swami@ump.edu.pl

Received 31 March 2017; Accepted 1 August 2017; Published 10 September 2017

Academic Editor: Leah Siskind

\begin{abstract}
Copyright ( 92017 Slawomir Michalak et al. This is an open access article distributed under the Creative Commons Attribution License, which permits unrestricted use, distribution, and reproduction in any medium, provided the original work is properly cited.
\end{abstract}

Objective. Mitochondrial dysfunction is considered a unifying pathophysiological explanation for movement disorders. Sirtuin 3 (SIRT3) exhibits deacetylase activity and antioxidant properties. The aim of the study was to analyze the mitochondrial respiration in peripheral blood mononuclear cells (PBMCs) and the SIRT3 activity in patients with movement disorders. Methods. Mitochondrial respiration was analyzed in intact PBMCs using the ROUTINE, LEAK, electron transfer system (ETS), and residual oxygen consumption (ROX) protocol by means of high-resolution respirometry. The SIRT3 expression and PBMC activity were measured using fluorometry. Ultrasound measurements of the echogenicity of the substantia nigra and the diameter of the 3 rd ventricle were also performed. Results. Patients with movement disorders exhibited a lower ROUTINE respiration than controls $(P=0.0237)$. Reduced oxygen fluxes in the LEAK $(P=0.033)$ and $\operatorname{ROX}(P=0.0486)$ states were observed in patients with movement disorders compared with controls. Decreased ROUTINE respiration $(P=0.007)$ and oxygen flux in the LEAK state $(P=0.0203)$ were observed in patients with PD with substantia nigra hyperechogenicity compared with controls. Decreased SIRT 3 deacetylase activity was found in patients with movement disorders. Conclusion. Impaired mitochondrial respiration in intact PBMCs was associated with inhibited SIRT3 activity and neurodegeneration measures evaluated using ultrasound in patients with PD.

\section{Introduction}

Movement disorders constitute a group of degenerative conditions in the central nervous system, including primarily Parkinson's disease (PD), atypical parkinsonian syndromes, dystonia, essential tremor, and restless legs syndrome. The idiopathic form of PD affects $1 \%$ of the population over 65 years of age with the incidence of 8-18 cases per 100,000 persons per year. With a prevalence of approximately $3 \%$ in persons over 75 years of age, neurodegenerative diseases are confirmed to develop predominantly in the elderly and are a major cause of disability in this population [1].

In contrast to idiopathic $\mathrm{PD}$, other movement disorders like progressive supranuclear palsy (PSP, SteeleRichardson-Olszewski's disease), corticobasal degeneration (CBD), multisystem atrophy (MSA), and diffuse Lewy 
body disease (DLBD) were considered atypical parkinsonism (AP).

Mitochondrial dysfunction was suggested as a unifying pathophysiological explanation for PD and other neurodegenerative disorders. Mitochondria are the most efficient producers of adenosine triphosphate (ATP) and play an important role in calcium homeostasis and in the initiation of apoptosis. In the case of severe oxidative phosphorylation defects, the ability of mitochondria to handle calcium is impaired [2]. Moreover, mitochondria are a major source of reactive oxygen species (ROS), including manganese superoxide dismutase (Mn-SOD, SOD2), and promote defense mechanisms against ROS-mediated damage. Hence, mitochondrial and oxidative stress are implicated in a number of neurodegeneration and aging-related disorders. Genes associated with autosomal recessive PD are reported to be involved in the control of the mitochondrial function. Phosphatase/tensin homolog deleted on chromosome 10- (PTEN-) induced putative kinase 1 (PINK1) and Parkin genes controls the elimination of impaired mitochondria via autophagy (mitophagy) [3].

Phosphorous magnetic resonance spectroscopy revealed impairments in the mitochondrial function in patients with PSP. Moreover, oxidative metabolism in the brain and skeletal muscles of patients with PSP was also reduced [4].

Movement disorders associated with alpha-synuclein ( $\alpha$-syn) pathology (PD, MSA, DLBD) are classified as synucleinopathies, while others associated with tau pathology like PSP and CBD are classified as tauopathies.

The role of $\alpha$-syn in the pathophysiology of PD seems to be dichotomous and awaits further elucidation. This small $14-\mathrm{kDa}$ (140 amino acids) presynaptic protein, with a propensity to aggregate into oligomers in a prion-like manner [5] and to form intraneuronal protein inclusions called Lewy bodies, can participate in defense mechanisms preserving the neural mitochondrial homeostasis against oxidative stress, without protecting against stressors directly affecting mitochondrial function [6]. Mutations in the SNCA1 gene, which encodes $\alpha$-syn, cause familial PD and are risk factors for sporadic PD [7]. Accumulation of $\alpha$-syn aggregates in neurons is a key process in the PD pathogenesis. These aggregates are found not only in the substantia nigra pars compacta in PD but also in other neurons in the central and peripheral nervous system $[8,9]$. There are conflicting reports on the role of $\alpha$-syn in the production of proinflammatory cytokines in microglia or monocytes [10-13]. The expression of $\alpha$-syn in peripheral blood mononuclear cells (PBMCs) was found to be upregulated in idiopathic PD [14]. Moreover, in healthy humans, $\alpha$-syn expression was detected in PBMCs, T lymphocytes, B lymphocytes, natural killer cells, and monocytes [15]. It has been also reported that $\alpha$-syn plays an important role in the development and function of $\mathrm{T}$ lymphocytes [16].

Sirtuin 3 (SIRT3) is a member of the silent information regulator 2 (Sir2) protein family. It is classified as class I SIRT together with SIRT1 and SIRT2, all of which exhibit a deacetylase activity in the presence of oxidized nicotinamide adenine dinucleotide $\left(\mathrm{NAD}^{+}\right)$[17]. SIRT3, SIRT4, and SIRT5 are all located in mitochondria, and SIRT3 is considered an enzyme of the mitochondrial matrix [18]. In addition, SIRT3 catalyzes the deacetylation of two enzymes important for antioxidative protection, namely, SOD2 and isocitrate dehydrogenase 2 (IDH2). The activation of SOD2 and IDH2 mediates the antioxidant effect of SIRT3 [19]. The neuroprotective action of SIRT3 was also reported in neurodegenerative disorders such as Alzheimer's disease [20] and recently in an experimental model of PD [21]. SIRT3 expression was also evident in PBMCs [22].

Thus, PBMCs, which can be obtained with minimally invasive procedures, may serve as a model for studying the relationship between neurodegeneration and immunity in patients with neurodegenerative disorders. Moreover, the metabolic pathways of PBMCs occur also in the nervous system (e.g., glutamate pathways). In addition, in pathological (inflammatory/immune) conditions, the PBMCs can penetrate into the central nervous system through the bloodbrain barrier (BBB) and cause local effects. In an animal model of experimental autoimmune encephalitis, the migration of PBMCs across the $\mathrm{BBB}$ was reported with the involvement of chemokines [23, 24]. The intracellular domain of brain endothelial intercellular adhesion molecule 1 (ICAM-1 or CD54) is required for the transmigration of $\mathrm{T}$ lymphocytes through the BBB [25]. Moreover, the penetration of activated monocytes through the BBB is mediated by signal transduction via the tumor necrosis factor (TNF) receptor 1 (TNFR1) [26]. In an animal model of neurodegeneration, PBMC transmigration was also demonstrated [27].

Based on these previous findings, we aimed to study the mitochondrial respiration in intact PBMCs in relation to the expression and activity of SIRT3 in patients with movement disorders.

\section{Material and Methods}

2.1. Patients. The study included 57 patients with movement disorders. Idiopathic PD was represented by 38 patients (age $60 \pm 9$ years), while 19 patients were diagnosed with AP (age $63 \pm 10$ years), including PSP $(n=6)$, CDB $(n=3)$, MSA $(n=9)$, and DLBD $(n=1)$.

The following data were extracted from the patients' medical history: (1) duration of disease, (2) presence of motor fluctuations and dyskinesias, (3) comorbidities, and (4) treatment. All patients underwent standard neurological examination. Patients with symptoms of any acute disease (e.g., inflammation, infection, and metabolic imbalance) or exacerbation of chronic comorbidities were excluded from the study. In addition, 10 healthy, age-matched volunteers were enrolled in the study as controls. Written informed consent was obtained from all the participants. The study protocol was accepted by the Bioethics Committee of Poznan University of Medical Sciences.

2.2. PBMC Isolation and Preparation. PBMCs were isolated from ethylenediaminetetraacetic acid (EDTA) blood via density gradient centrifugation (Histopaque, Sigma-Aldrich). The isolated fractions were supplemented with protease inhibitor cocktails (Sigma-Aldrich; 1:200 vol/vol) on ice. 

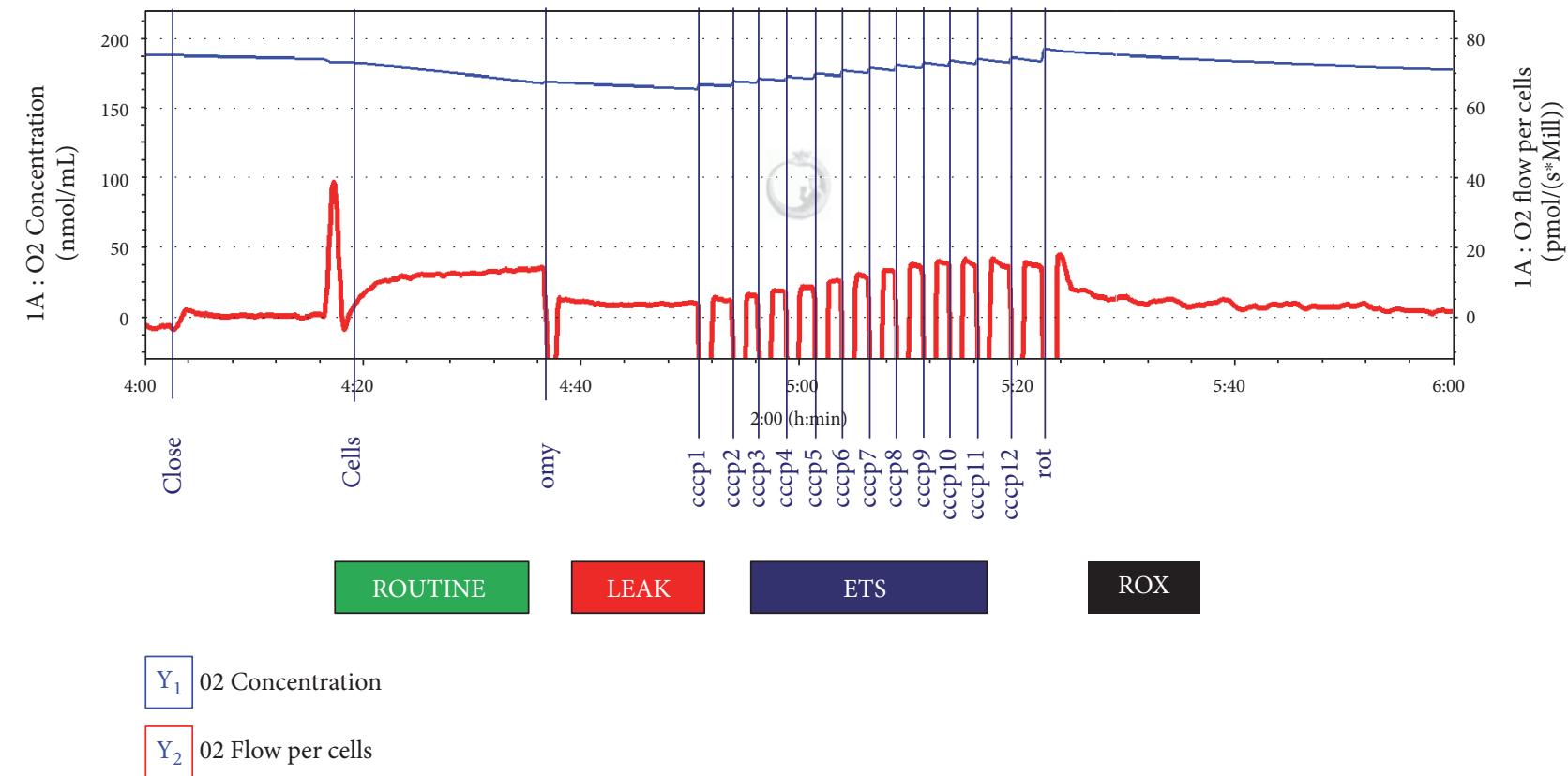

FIgURE 1: ROUTINE, LEAK, electron transfer system capacity (ETS), and residual oxygen consumption (ROX) respiration in intact peripheral blood mononuclear cells (PBMCs). A record of the protocol during high-resolution respirometry recorded with the use of DatLab software.

The cell number was counted in Bürker's chamber and the volume corresponding to $10^{6}$ cells was applied for respirometry. Cell viability was tested using the Trypan blue method.

For the SIRT3 analyses, PBMCs were incubated for $30 \mathrm{~min}$ in lysis buffer $(150 \mathrm{mM} \mathrm{NaCl}, 50 \mathrm{mM}$ Tris- $\mathrm{HCl}$ $(\mathrm{pH}=8.0), 5 \mathrm{mM}$ EDTA, and $1 \% \mathrm{vol} / \mathrm{vol}$ Triton X100) with protease inhibitor cocktails (Sigma-Aldrich; $1: 200 \mathrm{vol} / \mathrm{vol}$ ) on ice. Subsequently, the lysate was centrifuged for $10 \mathrm{~min}$ at $20,000 \times g$. Protein contents in the PBMC lysates were evaluated using the Lowry method [28].

2.3. High-Resolution Respirometry. Mitochondrial respiration was analyzed in intact PBMCs according to the ROUTINE, LEAK, electron transfer system (ETS), and residual oxygen consumption (ROX) protocol [29] using a highresolution respirometer (Oxygraph-2k; Oroboros Instruments, Innsbruck, Austria). Briefly, a total of $10^{6}$ PBMCs were added to the respirometer chamber after $10 \mathrm{~min}$ of stabilization at $37^{\circ} \mathrm{C}$ and incubated with continuous stirring at a speed of $750 \mathrm{rpm}$. The data were subsequently collected with the application of DatLab software 6.1.0.7 (Oroboros Instruments, Innsbruck, Austria).

ROUTINE respiration in intact PBMCs represents the physiological energy turnover in mitochondria at intracellular nonsaturating adenosine diphosphate (ADP) levels based only on endogenous substrates, that is, without external supply of substrates. The LEAK state is induced by the administration of oligomycin ( $2 \mu \mathrm{L}, 2 \mathrm{mg} / \mathrm{mL}$ concentration), which is an inhibitor of ATP synthase, that is, the phosphorylation system. The LEAK state is a resting, oxygen flux, which compensates proton leak, proton slip, and circulation across the inner mitochondrial membrane. The ETS capacity is the maximum oxygen flux induced by an optimal administration of uncoupler (carbonyl cyanide m-chlorophenyl hydrazone, CCCP, $5 \mu \mathrm{L}$ steps, $1 \mathrm{mM}$ concentration). The ROX state was subsequently induced by administration of rotenone ( $10 \mu \mathrm{L}, 2.5 \mu \mathrm{M}$ concentration), an inhibitor of complex I, thus leading to nicotinamide adenine dinucleotide (NADH) oxidation. The ROX state reflects active oxidative side reactions after ETS inhibition (Figure 1).

2.4. SIRT3 Expression and Activity. The activity of SIRT3 was measured by means of a fluorometric method using the SIRT3 Activity Assay Kit (Abcam, Cambridge, UK). Three types of blanks were analyzed: one without patient sample, one without enzyme recombinant, and one without $\mathrm{NAD}^{+}$, and the respective volumes were substituted with doubledistilled water. The standard curve for SIRT3 expression in PBMCs was fitted using analyses of $0.5,1.0,1.5$, and $2.0 \mu \mathrm{g}$ of recombinant SIRT3. Deacetylase activity of SIRT3 was evaluated using kinetic measurements at $2 \mathrm{~min}$ intervals using a microtiter plate fluorometer (FLx800, BioTek Instruments, USA) with an excitation set at $340-360 \mathrm{~nm}$ and emission at $440-460 \mathrm{~nm}$ during $30 \mathrm{~min}$. The rate of reaction was calculated while the reaction velocity remained constant. The expression of SIRT3 was evaluated by means of endpoint measurements based on the calibration curve using recombinant SIRT3 (Abcam, Cambridge, UK). The expression of SIRT3 in PBMCs was represented as $\mu \mathrm{g} / \mathrm{mg}$ of proteins and deacetylase activity as units (U)/mg of proteins.

2.5. Substantia Nigra Echogenicity and Measurement of the Diameter of the 3rd Ventricle. Transcranial ultrasound measurements of the substantia nigra echogenicity and the diameter of the 3 rd ventricle were performed using 
TABLE 1: Mitochondrial respiration and sirtuin 3 (SIRT3) expression/activity in patients with movement disorders and in controls. Results are presented as mean \pm standard deviation (ROUTINE, ROX) and median (interquartile range for LEAK, ETS, and SIRT3). All outcomes of mitochondrial respiration are measured in pmol O2/s* $10^{6}$ cells. SIRT3 protein expression is represented as $\mu \mathrm{g} / \mathrm{mg}$ protein. SIRT3 activity is represented as $\mathrm{U} / \mu \mathrm{g}$ protein.

\begin{tabular}{|c|c|c|c|}
\hline & $\begin{array}{c}\text { Controls } \\
n=10\end{array}$ & $\begin{array}{c}\text { Patients with } \\
\text { movement } \\
\text { disorders } \\
n=57\end{array}$ & $P$ \\
\hline $\begin{array}{l}\text { ROUTINE } \\
\left(\mathrm{pmol} \mathrm{O}_{2} / \mathrm{s}^{*} 10^{6} \text { cells }\right)\end{array}$ & $19.3 \pm 4.4$ & $15.3 \pm 4.5$ & 0.0237 \\
\hline $\begin{array}{l}\text { LEAK } \\
\left(\mathrm{pmol} \mathrm{O} / \mathrm{s}^{*} 10^{6} \text { cells }\right)\end{array}$ & $\begin{array}{c}6.02 \\
5.37-6.78\end{array}$ & $\begin{array}{c}4.2 \\
2.98-5.68\end{array}$ & 0.033 \\
\hline $\begin{array}{l}\text { ETS } \\
\left(\mathrm{pmol} \mathrm{O} / \mathrm{s}^{*} 10^{6} \text { cells }\right)\end{array}$ & $\begin{array}{c}13.34 \\
11.22-17.39\end{array}$ & $\begin{array}{c}12.21 \\
9.84-15.79\end{array}$ & 0.4168 \\
\hline $\begin{array}{l}\operatorname{ROX} \\
\left(\mathrm{pmol} \mathrm{O} / \mathrm{s}^{*} 10^{6} \text { cells }\right)\end{array}$ & $5.7 \pm 1.6$ & $4.2 \pm 2.0$ & 0.0486 \\
\hline $\begin{array}{l}\text { SIRT3 expression } \\
\text { ( } \mu \mathrm{g} / \mathrm{mg} \text { protein) }\end{array}$ & $\begin{array}{c}63.9 \\
20.5-115.4\end{array}$ & $\begin{array}{c}35.4 \\
23.2-57.9\end{array}$ & 0.4309 \\
\hline $\begin{array}{l}\text { SIRT3 activity } \\
\text { (U/ } \mu \text { g protein) }\end{array}$ & $\begin{array}{c}181.17 \\
60.9-344.6\end{array}$ & $\begin{array}{c}71.40 \\
38.7-132.9\end{array}$ & 0.0178 \\
\hline
\end{tabular}

ALOKA Prosound Alpha 7 device according to standard procedures.

2.6. Statistics. Statistical analyses were performed using the licensed MedCalc software version 16.8.4-64 bit. First, the distribution of the variables was tested using the D'Agostino-Pearson test. Subsequently, the results with a Gaussian distribution were analyzed using Student's $t$-test for independent variables and expressed as mean \pm standard deviation (SD), while those with a non-Gaussian distribution were analyzed with Mann-Whitney $U$ test and expressed as median (interquartile range). The significance level (alpha level) was set at or below 0.05 .

\section{Results}

The results indicated that ROUTINE respiration in PBMCs was reduced in patients with movement disorders compared with healthy controls (Table 1). Oxygen fluxes in LEAK and ROX states were also lower in patients with movement disorders than in controls (Table 1). No differences in mitochondrial respiration in PBMCs were observed between patients with PD and AP (Table 2).

Among patients with movement disorders, 59\% showed substantia nigra hyperechogenicity (Figure 2(b)) with an area of $0.22 \pm 0.02 \mathrm{~cm}^{2}$ (mean $\left.\pm \mathrm{SD}\right)$. The diameter of the 3rd ventricle was $7.2 \pm 2.5 \mathrm{~mm}$ in patients with movement disorders, while the reference value was $4.0 \pm 0.74 \mathrm{~mm}$ [30].

ROUTINE respiration was inhibited in patients with PD exhibiting substantia nigra hyperechogenicity (Figure 2) compared with controls (Table 3). The oxygen flux in the LEAK state was lower in patients with PD with substantia nigra hyperechogenicity than in healthy controls (Table 3 ).
We have not found differences in the expression of SIRT3 protein in PBMCs from patients with movement disorders and controls; however, the deacetylase activity was significantly lower in patients with movement disorders (Table 1). The SIRT3 deacyetylase activity was downregulated in patients with PD compared with controls, while no differences between PD and AP were observed (Table 2). Furthermore, there was no association between SIRT3 expression in PBMCs and the substantia nigra hyperechogenicity (Table 3). Interestingly, the SIRT3 deacetylase activity was inhibited in patients with movement disorders without substantia nigra echogenicity (Table 3 ).

ROUTINE respiration and ROX correlated negatively with the diameter of the 3 rd ventricle measured using ultrasound ( $r=-0.3820, P=0.0373$ and $r=-0.3969, P=0.0330$, resp.) in patients with movement disorders. ROX correlated negatively with the age of patients with movement disorders $(r=-0.2724, P=0.0463)$.

In patients without hyperechogenicity of the substantia nigra, LEAK respiration correlated negatively $(r=-0.636$, $P=0.0353)$ with SIRT3 expression in PBMCs.

In our group of patients, 48 (84\%) had movement disorders, which were classified as synucleinopathies (PD, MSA, and DLBD). There were no differences in the mitochondrial respiration between patients with synucleinopathies and patients without $\alpha$-syn pathology (Figure 3). Moreover, there was no difference in the SIRT3 activity or its expression in patients with movement disorders related to synucleinopathy (66.8; $41.9-111.8 \mathrm{U} / \mu \mathrm{g}$ protein and $35.5 ; 23.1-58.7 \mu \mathrm{g} / \mathrm{mg}$ protein) compared with patients without synucleinopathy $(104.8 ; 30.9-146.2 \mathrm{U} / \mu \mathrm{g}$ protein; median, interquartile range, $P=0.6652$ and $36.6 ; 28.5-57.7 \mu \mathrm{g} / \mathrm{mg}$ protein, median, interquartile range, $P=0.7913)$. In movement disorders without $\alpha$-syn pathology ( $n=9$, PSP and CDB), we have found a positive correlation $(r=0.714 ; P=0.0465)$ between ROUTINE respiration and SIRT3 expression in PBMCs and positive correlation between ROX and SIRT3 expression in PBMCs $(r=0.833 ; P=0.0102)$. We have not found correlation between SIRT3 activity or SIRT3 expression and duration of movement disorders. There was also no association between SIRT3 activity or SIRT3 expression in early and late stages of movement disorders.

No differences in mitochondrial respiration in intact PBMCs were observed between treated (1) and untreated (0) patients with movement disorders, regardless of the treatment, which consisted of levodopa, dopamine receptor agonists (ropinirole, pramipexole), selegiline, rasagiline, or amantadine (Figure 4). Similarly, no differences in SIRT3 expression/activity were noticed between treated and nontreated patients with movement disorders (Figure 4).

\section{Discussion}

The present study indicated that primary neurodegenerative movement disorders, particularly idiopathic $\mathrm{PD}$, are associated with impaired mitochondrial respiration in intact PBMCs and with reduced SIRT3 activity.

The impairment of mitochondrial function, particularly in association with complex I downregulation, has been 
TABLE 2: Mitochondrial respiration and sirtuin 3 (SIRT3) expression/activity in patients with Parkinson's disease (PD), atypical parkinsonism (AP), and controls $(\mathrm{C})$. Results are presented as mean \pm standard deviation (ROUTINE and ROX) and median (interquartile range for LEAK, ETS, and SIRT3). All outcomes of mitochondrial respiration are measured in pmol O2/s* $10^{6}$ cells. SIRT3 protein expression is represented as $\mu \mathrm{g} / \mathrm{mg}$ protein. SIRT3 activity is represented as $\mathrm{U} / \mu \mathrm{g}$ protein.

\begin{tabular}{|c|c|c|c|c|c|c|}
\hline & $\begin{array}{c}\text { Controls }(\mathrm{C}) \\
n=10\end{array}$ & $\begin{array}{c}\text { Patients with } \\
\text { Parkinson's disease (PD) } \\
n=38\end{array}$ & $\begin{array}{l}\text { Patients with atypical } \\
\text { parkinsonism (AP) } \\
n=19\end{array}$ & $\mathrm{P}-\mathrm{PD}$ versus $\mathrm{C}$ & $\mathrm{P}-\mathrm{AP}$ versus $\mathrm{C}$ & $P D$ versus $A P$ \\
\hline $\begin{array}{l}\text { ROUTINE } \\
\left(\mathrm{pmol} \mathrm{O} / \mathrm{s} * 10^{6} \text { cells }\right)\end{array}$ & $19.3 \pm 4.4$ & $15.2 \pm 4.1$ & $15.7 \pm 5.3$ & 0.0143 & 0.644 & 0.6518 \\
\hline $\begin{array}{l}\text { LEAK } \\
\left(\mathrm{pmol} \mathrm{O}_{2} / \mathrm{s}^{*} 10^{6} \text { cells }\right)\end{array}$ & $\begin{array}{c}6.02 \\
5.37-6.78\end{array}$ & $\begin{array}{c}4.1 \\
2.97-5.41\end{array}$ & $\begin{array}{c}4.24 \\
3.57-6.95\end{array}$ & 0.0138 & 0.2665 & 0.3089 \\
\hline $\begin{array}{l}\text { ETS } \\
\left(\mathrm{pmol} \mathrm{O} / \mathrm{s}^{*} 10^{6} \text { cells }\right)\end{array}$ & $\begin{array}{c}13.34 \\
11.22-17.39\end{array}$ & $\begin{array}{c}12.03 \\
9.61-15.45\end{array}$ & $\begin{array}{c}13.1 \\
10.56-17.23\end{array}$ & 0.4171 & 0.5050 & 0.4828 \\
\hline $\begin{array}{l}\text { ROX } \\
\left(\mathrm{pmol} \mathrm{O}_{2} / \mathrm{s}^{*} 10^{6} \text { cells }\right)\end{array}$ & $5.7 \pm 1.6$ & $\begin{array}{c}3.75 \\
2.61-5.52\end{array}$ & $3.92 \pm 1.98$ & 0.0430 & 0.0754 & 0.9604 \\
\hline $\begin{array}{l}\text { SIRT3 expression } \\
\text { ( } \mu \mathrm{g} / \mathrm{mg} \text { protein) }\end{array}$ & $\begin{array}{c}63.9 \\
20.5-115.4\end{array}$ & $\begin{array}{c}37.1 \\
22.2-59.5\end{array}$ & $\begin{array}{c}35.4 \\
24.0-57.9\end{array}$ & 0.4309 & 0.5952 & 0.9429 \\
\hline $\begin{array}{l}\text { SIRT3 activity } \\
\text { (U/ } \mu \text { g protein) }\end{array}$ & $\begin{array}{c}181.17 \\
60.9-344.6\end{array}$ & $\begin{array}{c}66.8 \\
43.9-111.8\end{array}$ & $\begin{array}{c}77.4 \\
30.9-146.2\end{array}$ & 0.0195 & 0.0570 & 0.8312 \\
\hline
\end{tabular}

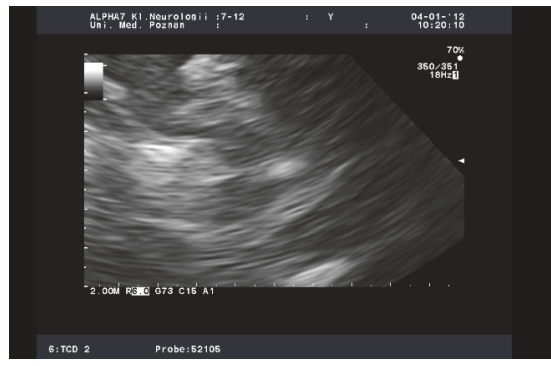

(a)

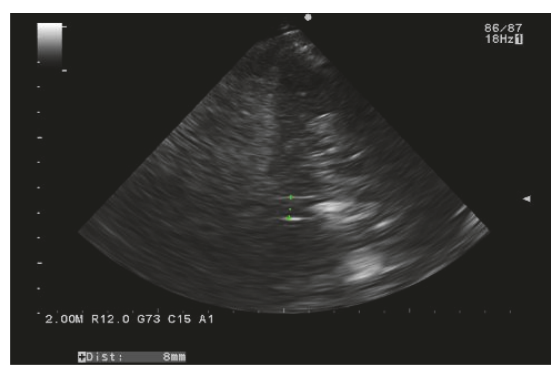

(c)

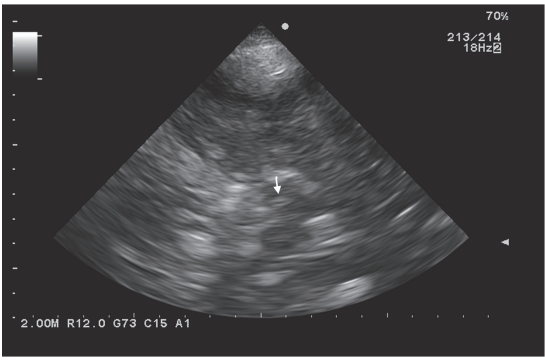

(b)

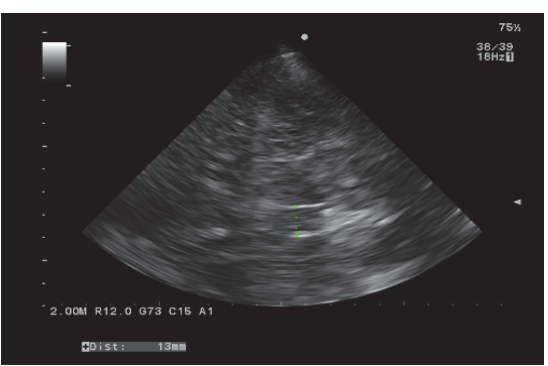

(d)

FIGURE 2: Ultrasound examination of the substantia nigra in a representative control (a) and patient with Parkinson's disease (PD) (b). The arrow in (b) indicates hyperechogenicity. The vertical green dotted line indicates normal 3rd ventricle in the healthy participant (c) and dilated 3rd ventricle in the patient with PD (d).

extensively studied in brains of patients with $\mathrm{PD}[31,32]$. Moreover, mitochondrial pathology was also suggested in other movement disorders. In patients with PSP, a decreased activity of o-ketoglutarate dehydrogenase in the frontal cortex has been reported, while the activities of complexes I and IV remained unaffected [33]. MSA in animals is induced by chronic administration of 3-nitropropionic acid, which inhibits mitochondrial complex II [34]. In Lewy body disorders, rare variants in the mitochondrial-targeting sequence (MTS) domain of the coiled-coil-helix-coiled-coil-helix domain containing 2 protein encoding genes ( $\mathrm{CHCHD} 2)$ have been identified [35].

Mitochondria were also studied in non-neural tissues and cells. Shinde and Pasupathy [36] reported disturbances in mitochondrial respiration in lymphocytes in patients with $\mathrm{PD}$ on the basis of the activity measurements of succinate cytochrome $c$ reductase (complexes II and III), rotenone-sensitive NADH cytochrome c reductase (complexes I and III), citrate synthase, succinate dehydrogenase (complex II), and cytochrome c oxidase (complex IV). 
TABLE 3: Comparison of mitochondrial respiration and sirtuin 3 (SIRT3) expression/activity in a subgroup of patients with movement disorders with substantia nigra hyperechogenicity and in controls. Results are presented as mean \pm standard deviation (ROUTINE and ROX) and median (interquartile range for LEAK, ETS, and SIRT3). All outcomes of mitochondrial respiration are measured in pmol $\mathrm{O} 2 / \mathrm{s}^{*} 10^{6}$ cells. SIRT3 protein expression is represented as $\mu \mathrm{g} / \mathrm{mg}$ protein. SIRT3 activity is represented as U/ $\mu \mathrm{g}$ protein.

\begin{tabular}{|c|c|c|c|c|c|c|}
\hline & $\begin{array}{l}\text { Controls } \\
\qquad \begin{array}{l}\text { (C) } \\
n=10\end{array}\end{array}$ & $\begin{array}{c}\text { Substantia nigra } \\
\text { hyperechogenicity } \\
\text { present }(\mathrm{SNH}+) \\
(59 \%)\end{array}$ & $\begin{array}{c}\text { Substantia nigra } \\
\text { hyperechogenicity } \\
\text { absent (SNH-) } \\
(41 \%)\end{array}$ & $\begin{array}{l}P(\mathrm{SNH}+) \\
\text { versus C }\end{array}$ & $\begin{array}{l}P(\mathrm{SNH}-) \\
\text { versus C }\end{array}$ & $\begin{array}{c}P(\mathrm{SNH}+) \\
\text { versus }(\mathrm{SNH}-)\end{array}$ \\
\hline $\begin{array}{l}\text { ROUTINE } \\
\left(\mathrm{pmol} \mathrm{O}_{2} / \mathrm{s}^{*} 10^{6} \text { cells }\right)\end{array}$ & $19.3 \pm 4.4$ & $14.1 \pm 3.6$ & $15.9 \pm 4.9$ & 0.007 & 0.1332 & 0.3768 \\
\hline $\begin{array}{l}\text { LEAK } \\
\left(\mathrm{pmol} \mathrm{O}_{2} / \mathrm{s}^{*} 10^{6} \text { cells }\right)\end{array}$ & $\begin{array}{c}6.02 \\
5.37-6.78\end{array}$ & $\begin{array}{c}3.4 \\
2.1-5.2\end{array}$ & $\begin{array}{c}4.4 \\
3.6-5.5\end{array}$ & 0.0203 & 0.0822 & 0.6603 \\
\hline $\begin{array}{l}\text { ETS } \\
\left(\mathrm{pmol} \mathrm{O} / \mathrm{s}^{*} 10^{6} \text { cells }\right)\end{array}$ & $\begin{array}{c}13.34 \\
11.22-17.39\end{array}$ & $\begin{array}{c}12.1 \\
9.9-15.2\end{array}$ & $\begin{array}{c}12.2 \\
9.3-14.3\end{array}$ & 0.1947 & 0.3465 & 0.9167 \\
\hline $\begin{array}{l}\text { ROX } \\
\left(\mathrm{pmol} \mathrm{O} / \mathrm{s}^{*} 10^{6} \text { cells }\right)\end{array}$ & $5.7 \pm 1.6$ & $4.1 \pm 2.0$ & $4.1 \pm 2.5$ & 0.0801 & 0.1337 & 0.9484 \\
\hline $\begin{array}{l}\text { SIRT3 expression } \\
\text { ( } \mu \mathrm{g} / \mathrm{mg} \text { protein })\end{array}$ & $\begin{array}{c}63.9 \\
20.5-115.4\end{array}$ & $\begin{array}{c}35.5 \\
24.0-47.8\end{array}$ & $\begin{array}{c}42.7 \\
19.4-60.1\end{array}$ & 0.9606 & 0.6666 & 0.9606 \\
\hline $\begin{array}{l}\text { SIRT3 activity } \\
\text { (U/ } \mu \text { g protein) }\end{array}$ & $\begin{array}{c}181.17 \\
60.9-344.6\end{array}$ & $\begin{array}{c}90.1 \\
37.3-141.2\end{array}$ & $\begin{array}{c}66.6 \\
34.7-137.3\end{array}$ & 0.6570 & 0.0364 & 0.6570 \\
\hline
\end{tabular}

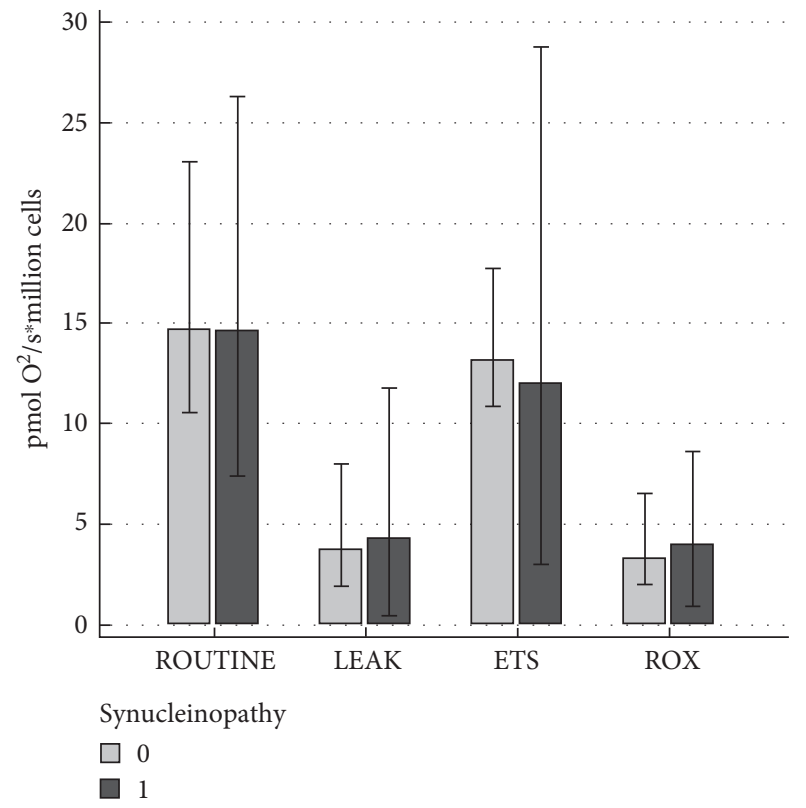

Figure 3: Comparison of the mitochondrial respiration in peripheral blood mononuclear cells (PBMCs) in patients classified to the group of synucleinopathy-related movement disorders (1) and without synucleinopathy $(0)$.

The downregulation of rotenone-sensitive NADH cytochrome c reductase (complexes I and III) and cytochrome c oxidase (complex IV) was observed in parkinsonian patients and was associated with a decreased ratio of complexes I and III to complexes II and III [36]. Other studies on the mitochondria of lymphocytes revealed an inhibition of complex II [37] and complex IV [38] activities, while studies on isolated mitochondria showed normal activities [39]. In leukocytes isolated from patients with $\mathrm{PD}$, the activities of complexes I and IV were decreased; however, in patients with PARKIN gene mutations, the activity of complex IV was unchanged [40].

The studies on the platelets' mitochondria contributed conflicting data. For example, normal mitochondrial function was observed [41-44], along with downregulated activities of complex I [37, 45-49], complex II + III [48], or complex IV [47].

In skin fibroblast cultures from patients with $\mathrm{PD}$, the inhibition of complex $\mathrm{V}$ activity was reported, although the levels of oxidized, reduced, and total coenzyme Q10 and activities of $\mathrm{Cu} / \mathrm{Zn}$ - and $\mathrm{Mn}-\mathrm{SOD}$, glutathione peroxidase, and catalase remained unchanged [50].

Our results showing a decreased ROUTINE respiration in PBMCs of patients with movement disorders are in concordance with conclusions of most of the abovementioned studies. However, we have used a high-resolution respirometry instead of the analyses of enzymatic activity evaluations. Analyses in our study were performed in intact PBMCs and in real time. Reduced ROUTINE respiration in intact PBMCs reflects a decreased energy turnover in the mitochondrial and downregulated metabolic state. The decreased LEAK state in intact PBMCs from our patients with movement disorders indicates that the oxygen flux, which compensates the proton leak, proton slip, and cation circulation across the inner mitochondrial membrane, is impaired, particularly in patients with idiopathic PD. The reduced ROX observed in intact PBMCs from patients with movement disorders in our study indicates a rather downregulated nonmitochondrial respiration and, to some extent, a decreased non-ETS respiration. These results may also be the consequence of the depletion of endogenous substrates. All our observations indicated a mitochondrial dysfunction in patients with movement disorders and particularly PD.

ROUTINE and LEAK respirations were also decreased in patients with hyperechogenicity of the substantia nigra, while 


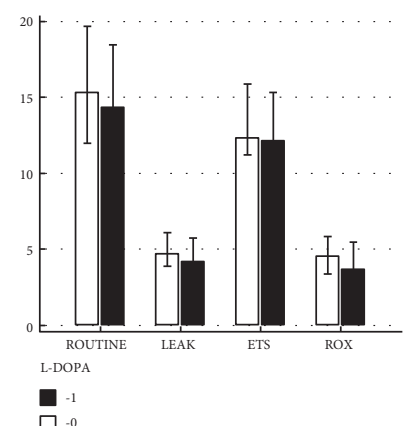

(a)

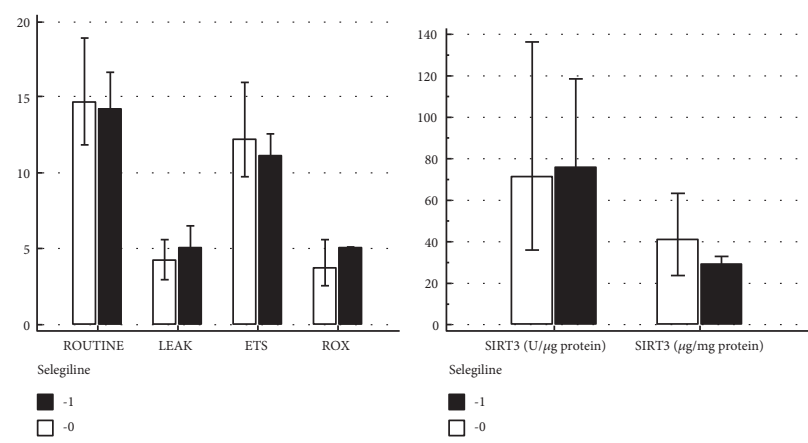

(c)

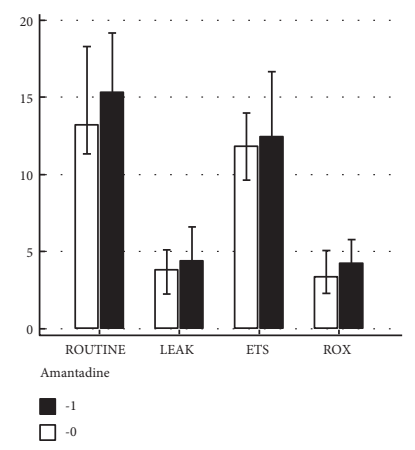

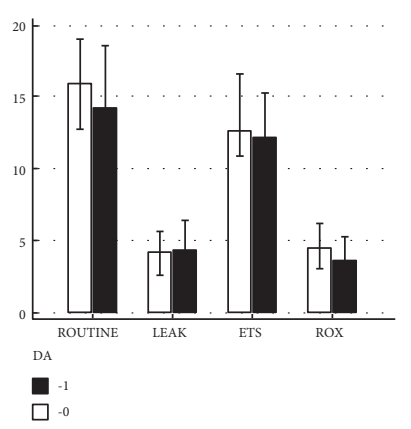

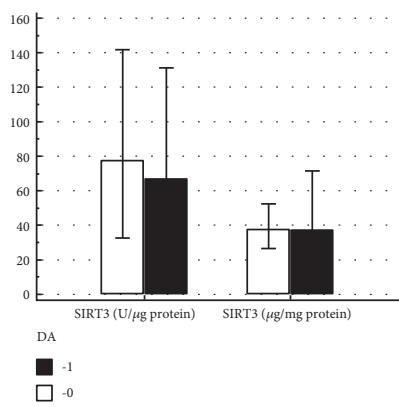

(b)
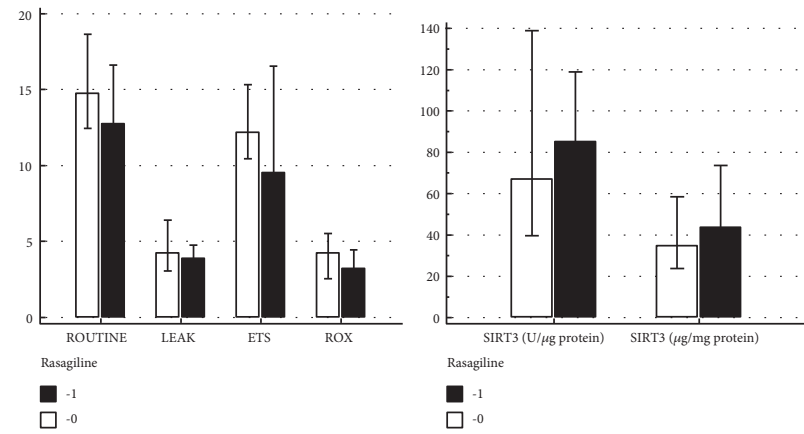

(d)

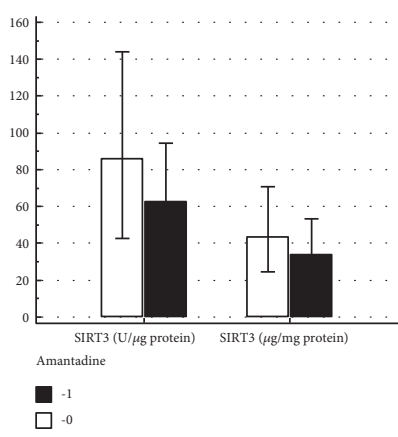

(e)

FIGURE 4: The mitochondrial respiration results and SIRT3 expression/activity in patients with movement disorders $(n=57)$ with respect to treatment (1) and no treatment (0) using (a) levodopa (L-DOPA; A0, $n=6$; A1, $n=51$ ); (b) dopamine (DA) receptor agonists ropinirole and pramipexole (B0, $n=20$; B1, $n=37$ ); (c) selegiline (C0, $n=52 ; \mathrm{C} 1, n=5$ ); (d) rasagiline (D0, $n=47$; D1, $n=10)$; and (e) amantadine (E0, $n=28 ; \mathrm{E} 1, n=29)$. The results are expressed as median (interquartile range).

ROUTINE and ROX correlated negatively with the diameter of the 3rd ventricle measured using ultrasound. Thus, the impairment of mitochondrial respiration is associated with ultrasound measures of neurodegeneration in patients with movement disorders, particularly with PD. Substantia nigra hyperechogenicity was observed in $91 \%$ of the patients with PD [51] and in only $9 \%$ of patients with AP like MSA and PSP [52]. It is still not clear what might be the cause of the substantia nigra hyperechogenicity in a transcranial ultrasound of the midbrain. The most likely explanation, which was confirmed in both animals and postmortem studies, speculated that this sign is the result of the accumulation of iron within this brain structure [53] and microglial activation [54]. This is consistent with the hypothesis on the role of iron metabolism disturbances in neurodegenerative diseases, including PD [55]. Iron bound to transferrin enters the mitochondria and reaches complex I via the transferrin/ transferrin receptor 2 pathway. The accumulation of transferrin in the mitochondria has been reported in a rotenone model of PD [56]. Moreover, the inhibition of the mitochondrial aconitase activity led to iron accumulation in mitochondria and such a process is exacerbated by ROS production [57]. The studies that contributed to the understanding of the association between mitochondrial metabolism, iron accumulation, and substantia nigra hyperechogenicity support our observations of impaired mitochondrial function and ultrasonological measures of neurodegeneration.

SIRT3 activity, but not SIRT3 protein content in PBMCs, was significantly reduced in our cohort of patients with movement disorders and particularly those with PD. In recent years, a number of studies reported a protective role of SIRT3 in neurodegenerative disorders. In a cellular 
model of PD, SIRT3 was demonstrated to catalyze deacetylation leading to the activation of mitochondrial enzyme citrate synthase [58]. SIRT3 maintains mitochondrial integrity by stimulating a variety of enzymes including SOD2 and glutathione peroxidase, which is involved in ROS scavenging [59]. The expression of SIRT3 together with SIRT5 was stimulated by $\alpha$-syn in PC12 cells, while SIRT1 expression was decreased [60]. Moreover, SIRT3 participates in the antioxidant response in activated microglia [61]. Despite the decreased SIRT3 activity in our patients, we have found a positive correlation between SIRT3 protein expression and mitochondrial respiration in PBMCs. This may indicate that SIRT3 is also involved in the protection of the mitochondrial respiration in patients with movement disorders. From the sirtuin gene family, only SIRT2 was shown as a modulator of proteotoxicity associated with PD [62]. The deacetylase activity of SIRT3 reduces the impact of subcellular stress on mitochondria via the stabilization of ETS and reduction of oxidative stress [63]. Such posttranslational modifications of SIRT3 activity can be a future therapeutic target.

In Chinese patients with $\mathrm{PD}$, polymorphisms in SIRT1 gene, such as g.69644133C>G, g.69644213G>A, and g.69644351G $>A$, have been identified [64]. However, in the Spanish PD population, no association between SIRT gene polymorphisms and PD was found [65]. A singlenucleotide polymorphism in SIRT5prom2 was reported to have an impact on brain aging and risk of neurodegeneration [66].

We found no differences neither in mitochondrial respiration nor in SIRT3 expression or activity in subgroups of patients with movement disorders treated with specific drugs. The main limitation of our present study was its open-label, observational nature. However, particularly noticeable was the absence of differences in the analyzed parameters between levodopa-treated and levodopa-naive patients. The safety of levodopa therapy was discussed for decades, but the drug remains a golden standard in the treatment of idiopathic PD in clinical practice. Nevertheless, levodopa toxicity has been also reported. For example, levodopa injured mitochondria in vitro in cell cultures via pro-oxidative processes [67]. Studies in animal models of PD also revealed toxic effects of levodopa [68]. On the other hand, levodopa showed protective [69] and antioxidant effects [70]. Thus, our observation is in concordance with the latter studies.

To conclude, idiopathic PD is associated with impaired mitochondrial respiration in intact PBMCs and reduced SIRT3 activity. The activity of respiratory states in intact PBMCs correlated with the SIRT3 activity and neurodegeneration measures in transcranial ultrasound examination of patients with PD. No differences in mitochondrial respiration in PBMC or SIRT3 activity were observed depending on the treatment.

\section{Conflicts of Interest}

The authors declare no conflict of interest.

\section{References}

[1] L. M. de Lau and M. M. Breteler, "Epidemiology of Parkinson's disease," Lancet Neurology, vol. 5, pp. 525-535, 2006.

[2] J. C. von Kleist-Retzow, H. T. Hornig-Do, M. Schauen et al., "Impaired mitochondrial $\mathrm{Ca}_{2}{ }^{+}$homeostasis in respiratory chain-deficient cells but efficient compensation of energetic disadvantage by enhanced anaerobic glycolysis due to low ATP steady state levels," Experimental and Celllar Research, vol. 313, pp. 3076-3089, 2007.

[3] A. M. Pickrell and R. J. Youle, "The roles of PINK1, parkin, and mitochondrial fidelity in Parkinson's disease," Neuron, vol. 85, pp. 257-273, 2015.

[4] P. Martinelli, C. Scaglione, R. Lodi, S. Iotti, and B. Barbiroli, "Deficit of brain and skeletal muscle bio-energetics in progressive supranuclear palsy shown in vivo by phosphorus magnetic resonance spectroscopy," Movement Disorders, vol. 15, pp. 889-893, 2000.

[5] M. Masuda-Suzukake, T. Nonaka, M. Hosokawa et al., "Prion-like spreading of pathological $\alpha$-synuclein in brain," Brain, vol. 136, pp. 1128-1138, 2013.

[6] S. Menges, G. Minakaki, P. M. Schaefer et al., "Alpha-synuclein prevents the formation of spherical mitochondria and apoptosis under oxidative stress," Scientific Reports, vol. 7, article 42942, 2017.

[7] M. H. Polymeropoulos, C. Lavedan, E. Leroy et al., "Mutation in the $\alpha$-synuclein gene identified in families with Parkinson's disease," Science, vol. 276, pp. 2045-2047, 1997.

[8] H. Braak, K. D. Tredici, H. Bratzke, J. Hamm-Clement, D. Sandmann-Keil, and U. Rub, "Staging of the intracerebral inclusion body pathology associated with idiopathic Parkinson's disease (preclinical and clinical stages)," Journal of Neurology, vol. 249, pp. 1-5, 2002.

[9] H. Braak, K. D. Tredici, U. Rub, R. A. de Vos, E. N. Jansen Steur, and E. Braak, "Staging of brain pathology related to sporadic Parkinson's disease," Neurobiology of Aging, vol. 24, pp. 197-211, 2003.

[10] Y. Couch, L. Alvarez-Erviti, N. R. Sibson, M. J. Wood, and D. C. Anthony, "The acute inflammatory response to intranigral $\alpha$-synuclein differs significantly from intranigral lipopolysaccharide and is exacerbated by peripheral inflammation," Journal of Neuroinflammation, vol. 8, p. 166, 2011.

[11] E. J. Lee, M. S. Woo, P. G. Moon et al., " $\alpha$-Synuclein activates microglia by inducing the expressions of matrix metalloproteinases and the subsequent activation of protease-activated receptor-1," Journal of Immunology, vol. 185, pp. 615-623, 2010.

[12] S. Cao, D. G. Standaert, and A. S. Harms, "The gamma chain subunit of Fc receptors is required for alpha-synucleininduced pro-inflammatory signaling in microglia," Journal of Neuroinflammation, vol. 9, p. 259, 2012.

[13] W. Zhang, T. Wang, Z. Pei et al., "Aggregated $\alpha$-synuclein activates microglia: a process leading to disease progression in Parkinson's disease," FASEB Journal, vol. 19, pp. 533-542, 2005.

[14] S. Kim, B. S. Jeon, C. Heo et al., " $\alpha$-Synuclein induces apoptosis by altered expression in human peripheral lymphocyte in Parkinson's disease," FASEB Journal, vol. 18, pp. 16151617, 2004.

[15] E. C. Shin, S. E. Cho, D.-K. Lee et al., "Expression patterns of a-synuclein in human hematopoietic cells and in Drosophila at different developmental stages," Molecules and Cells, vol. 10, pp. 65-70, 2000. 
[16] A. Shameli, W. Xiao, Y. Zheng et al., "A critical role for alphasynuclein in development and function of T lymphocytes," Immunobiology, vol. 221, pp. 333-340, 2016.

[17] J. Du, Y. Zhou, X. Su et al., "Sirt5 is a NAD-dependent protein lysine demalonylase and desuccinylase," Science, vol. 334, pp. 806-809, 2011.

[18] B. Schwer, B. J. North, R. A. Frye, M. Ott, and E. Verdin, "The human silent information regulator (Sir)2 homologue hSIRT3 is a mitochondrial nicotinamide adenine dinucleotidedependent deacetylase," Journal of Cellular Biology, vol. 158, pp. 647-657, 2002.

[19] X. Qiu, K. Brown, M. D. Hirschey, E. Verdin, and D. Chen, "Calorie restriction reduces oxidative stress by SIRT3mediated SOD2 activation," Cell and Metabolism, vol. 12, pp. 662-667, 2010.

[20] H. J. Weir, T. K. Murray, P. G. Kehoe et al., "CNS SIRT3 expression is altered by reactive oxygen species and in Alzheimer's disease," PLoS One, vol. 7, article e48225, 2012.

[21] J. Y. Zhang, Y. N. Deng, M. Zhang, H. Su, and Q. M. Qu, "SIRT3 acts as a neuroprotective agent in rotenone-induced Parkinson cell model," Neurochemical Research, vol. 41, pp. 1761-1773, 2016.

[22] A. Storka, G. Führlinger, M. Seper et al., "E. coli endotoxin modulates the expression of Sirtuin proteins in PBMC in humans," Mediators of Inflammation, vol. 2013, Article ID 876943, 6 pages, 2013.

[23] L. Izikson, R. S. Klein, I. F. Charo, H. L. Weiner, and A. D. Luster, "Resistance to experimental autoimmune encephalomyelitis in mice lacking the Cc chemokine receptor (Ccr2)," Journal of Experimental Medicine, vol. 192, pp. 1075-1080, 2000.

[24] D. Mahad, M. K. Callahan, K. A. Williams et al., "Modulating $\mathrm{CCR}_{2}$ and $\mathrm{CCL}_{2}$ at the blood-brain barrier: relevance for multiple sclerosis pathogenesis," Brain, vol. 129, pp. 212-223, 2006.

[25] J. Greenwood, C. L. Amos, C. E. Walters et al., "Intracellular domain of brain endothelial intercellular adhesion molecule1 is essential for T lymphocyte-mediated signaling and migration," Journal of Immunology, vol. 171, pp. 2099-2108, 2003.

[26] C. D'Mello, T. Le, and M. G. Swain, "Cerebral microglia recruit monocytes into the brain in response to tumor necrosis factor $\alpha$ signaling during peripheral organ inflammation," Journal of Neuroscience, vol. 29, no. 7, pp. 2089-2102, 2009.

[27] S. Kyrkanides, A. W. Miller, J. N. Miller et al., "Peripheral blood mononuclear cell infiltration and neuroinflammation in the $\mathrm{HexB}^{-/-}$mouse model of neurodegeneration," Journal of Neuroimmunology, vol. 203, no. 1, pp. 50-57, 2008.

[28] O. H. Lowry, N. R. Rosenbrough, A. L. Farr, and R. Randall, "Protein measurement with Folin phenol reagent," Journal of Biological Chemistry, vol. 193, pp. 265-275, 1951.

[29] E. Gnaiger and K. Renner-Sattler K, "High-resolution respirometry and coupling control protocol with intact cells: ROUTINE, LEAK, ETS, ROX," Mitochondrial Physiology Network, vol. 08, no. 09, pp. 1-8, 2014.

[30] M. Müller, R. Esser, K. Kötter, J. Voss, A. Müller, and P. Stellmes, "Width of 3. Ventricle: reference values and clinical relevance in a cohort of patients with relapsing remitting multiple sclerosis," The Open Neurology Journal, vol. 7, pp. 11-16, 2013.

[31] P. M. Keeney, J. Xie, R. A. Capaldi, and J. P. Bennett, "Parkinson's disease brain mitochondrial complex I has oxidatively damaged subunits and is functionally impaired and misassembled," Journal of Neuroscience, vol. 26, pp. 52565264, 2006.

[32] A. H. V. Schapira, J. M. Cooper, D. Dexter, J. B. Clark, P. Jenner, and C. D. Marsden, "Mitochondrial complex I deficiency in Parkinson's disease," Journal of Neurochemistry, vol. 54, pp. 823-827, 1990.

[33] D. S. Albers, S. J. Augood, L. H. C. Park et al., "Frontal lobe dysfunction in PSP: evidence for oxidative stress and mitochondrial impairment," Journal of Neurochemistry, vol. 74, pp. $878-881,2000$.

[34] N. Stefanova, F. Tison, M. Reindl, W. Poewe, and G. K. Wenning, "Animal models of multiple system atrophy," Trends in Neurosciences, vol. 28, pp. 501-506, 2005.

[35] K. Ogaki, S. Koga, M. G. Heckman et al., "Mitochondrial targeting sequence variants of the $\mathrm{CHCHD}_{2}$ gene are a risk for Lewy body disorders," Neurology, vol. 85, pp. 20162025, 2015.

[36] S. Shinde and K. Pasupathy, "Respiratory-chain enzyme activities in isolated mitochondria of lymphocytes from patients with Parkinson's disease: preliminary study," Neurolology of India, vol. 54, pp. 390-393, 2006.

[37] H. Yoshino, Y. Nakagawa-Hattori, T. Kondo, and Y. Mizuno, "Mitochondrial complex I and II activities of lymphocytes and platelets in Parkinson's disease," Journal of Neural Transmission (Parkinson's Disease Section), vol. 4, pp. 27-34, 1992.

[38] N. Barroso, Y. Campos, R. Huertas et al., "Respiratory chain enzyme activities in lymphocytes from untreated patients with Parkinson disease," Clinical Chemistry, vol. 39, pp. 667-669, 1993.

[39] M. A. Martín, J. A. Molina, F. J. Jiménez-Jiménez et al., "Respiratory chain enzyme activities in isolated mitochondria of lymphocytes from untreated Parkinson's disease patients. Grupo Centro de Trastornos del Movimiento," Neurology, vol. 46, pp. 1343-1346, 1996.

[40] M. Muftuoglu, B. Elibol, O. Dalmizrak et al., "Mitochondrial complex I and IV activities in leukocytes from patients with parkin mutations," Movement Disorders, vol. 19, pp. 544$548,2004$.

[41] V. Mann, J. M. Cooper, D. Krige, S. E. Daniel, A. H. Schapira, and C. D. Marsden, "Brain, skeletal muscle and platelet homogenate mitochondrial function in Parkinson's disease," Brain, vol. 115, pp. 333-342, 1992.

[42] D. Bravi, J. J. Anderson, F. Dagani et al., "Effect of aging and dopaminomimetic therapy on mitochondrial respiratory function in Parkinson's disease," Movement Disorders, vol. 7, pp. 228-231, 1992.

[43] C. I. Blake, E. Spitz, M. Leehey, B. J. Hoffer, and S. J. Boyson, "Platelet mitochondrial respiratory chain function in Parkinson's disease," Movement Disorders, vol. 12, pp. 3-8, 1997.

[44] H. A. Hanagasi, D. Ayribas, K. Baysal, and M. Emre, "Mitochondrial complex I, II/III, and IV activities in familial and sporadic Parkinson's disease," International Journal of Neurosciences, vol. 115, pp. 479-493, 2005.

[45] W. D. Parker, S. J. Boyson, and J. K. Parks, "Abnormalities of the electron transport chain in idiopathic Parkinson's disease," Annals of Neurology, vol. 26, pp. 719-723, 1989.

[46] D. Krige, M. T. Carrol, J. M. Cooper, C. D. Marsden, and A. H. Schapira, "'Platelet mitochondrial function in Parkinson's disease", The Royal Kings and Queens Parkinson Disease Research Group," Annals of Neurology, vol. 32, pp. 782-788, 1992. 
[47] R. Benecke, P. Strumper, and H. Weiss, "Electron transfer complexes I and IV of platelets are abnormal in Parkinson's disease but normal in Parkinson-plus syndromes," Brain, vol. 116, pp. 1451-1463, 1992.

[48] R. H. Haas, F. Nasirian, K. Nakano et al., "Low platelet mitochondrial complex I and complex II/III activity in early untreated Parkinson's disease," Annals of Neurology, vol. 37, pp. 714-722, 1995.

[49] M. Varghese, M. Pandey, A. Samanta, P. K. Gangopadhyay, and K. P. Mohanakumar, "Reduced NADH coenzyme Q dehydrogenase activity in platelets of Parkinson's disease, but not Parkinson plus patients, from an Indian population," Journal of the Neurological Sciences, vol. 279, pp. 39-42, 2009.

[50] P. del Hoyo, A. García-Redondo, F. de Bustos et al., "Oxidative stress in skin fibroblasts cultures from patients with Parkinson's disease," BMC Neurology, vol. 10, p. 95, 2010.

[51] D. Berg, C. Siefker, and G. Becker, "Echogenicity of the substantia nigra in Parkinson's disease and its relation to clinical findings," Journal of Neurology, vol. 248, pp. 684-689, 2001.

[52] U. Walter, L. Niehaus, T. Probst, R. Benecke, B. U. Meyer, and D. Dressler, "Brain parenchyma sonography discriminates Parkinson's disease and atypical parkinsonian syndromes," Neurology, vol. 60, pp. 74-77, 2003.

[53] D. Berg, "Disturbance of iron metabolism as a contributing factor to SN hyperechogenicity in Parkinson's disease: implications for idiopathic and monogenetic forms," Neurochemical Research, vol. 32, pp. 1646-1654, 2007.

[54] Y. Zhu, B. Wang, K. Tao et al., "Iron accumulation and microglia activation contribute to substantia nigra hyperechogenicity in the 6-OHDA-induced rat model of Parkinson's disease," Parkinsonism and Related Disorders, vol. 36, pp. 76-82, 2017.

[55] Y. Ke and Z. Ming Qian, "Iron misregulation in the brain: a primary cause of neurodegenerative disorders," Lancet Neurology, vol. 2, pp. 246-253, 2003.

[56] P. G. Mastroberardino, E. K. Hoffman, M. P. Horowitz et al., "A novel transferrin/TfR2-mediated mitochondrial iron transport system is disrupted in Parkinson's disease," Neurobiology of Disease, vol. 34, pp. 417-431, 2009.

[57] L.-P. Liang and M. Patel, "Iron-sulfur enzyme mediated mitochondrial superoxide toxicity in experimental Parkinson's disease," Journal of Neurochemistry, vol. 90, pp. 1076-1084, 2004.

[58] X. X. Cui, X. Li, S. Y. Dong, Y. J. Guo, T. Liu, and Y. C. Wu, "SIRT3 deacetylated and increased citrate synthase activity in PD model," Biochemical and Biophysical Research Communications, vol. 484, pp. 767-773, 2017.

[59] L. Liu, C. Peritore, J. Ginsberg, M. Kayhan, and G. Donmez, "SIRT3 attenuates MPTP-induced nigrostriatal degeneration via enhancing mitochondrial antioxidant capacity," Neurochemical Research, vol. 40, pp. 600-608, 2015.

[60] J. Motyl, P. L. Wencel, M. Cieślik, R. P. Strosznajder, and J. B. Strosznajder, "Alpha-synuclein alters differently gene expression of Sirts, PARPs and other stress response proteins: implications for neurodegenerative disorders," Molecular Neurobiology, 2017.

[61] P. Rangarajan, A. Karthikeyan, J. Lu, E. A. Ling, and S. T. Dheen, "Sirtuin 3 regulates Foxo3a-mediated antioxidant pathway in microglia," Neuroscience, vol. 311, pp. 398-414, 2015.

[62] R. M. de Oliveira, H. Vicente Miranda, L. Francelle et al., "The mechanism of sirtuin 2-mediated exacerbation of alpha-synuclein toxicity in models of Parkinson disease," PLoS Biolology, vol. 15, article e2000374, 2017.

[63] J. A. Gleave, L. R. Arathoon, D. Trinh et al., "Sirtuin 3 rescues neurons through the stabilisation of mitochondrial biogenetics in the virally-expressing mutant $\alpha$-synuclein rat model of parkinsonism," Neurobiology of Disease, vol. 106, pp. 133-146, 2017.

[64] A. Zhang, H. Wang, X. Qin, S. Pang, and B. Yan, "Genetic analysis of SIRT1 gene promoter in sporadic Parkinson's disease," Biochemical Biophysical Research Communication, vol. 422, pp. 693-696, 2012.

[65] S. Jesús, P. Gómez-Garre, F. Carrillo et al., "Genetic association of sirtuin genes and Parkinson's disease," Journal of Neurology, vol. 260, pp. 2237-2241, 2013.

[66] C. Glorioso, S. Oh, G. G. Douillard, and E. Sibille, "Brain molecular aging, promotion of neurological disease and modulation by sirtuin 5 longevity gene polymorphism," Neurobiology of Disease, vol. 41, pp. 279-290, 2011.

[67] S. W. Chan, R. A. Dunlop, A. Rowe, K. L. Double, and K. J. Rodgers, "L-DOPA is incorporated into brain proteins of patients treated for Parkinson's disease, inducing toxicity in human neuroblastoma cells in vitro," Experimental Neurology, vol. 238, pp. 29-37, 2012.

[68] A. A. Abdin and N. I. Sarhan, "Intervention of mitochondrial dysfunction-oxidative stress-dependent apoptosis as a possible neuroprotective mechanism of $\alpha$-lipoic acid against rotenoneinduced parkinsonism and L-dopa toxicity," Neuroscience Research, vol. 71, pp. 387-395, 2011.

[69] K. Koshimura, J. Tanaka, Y. Murakami, and Y. Kato, "Effects of dopamine and l-DOPA on survival of PC12 cells," Journal of Neuroscience Research, vol. 62, pp. 112-119, 2000.

[70] A. Agil, R. Durán, F. Barrero et al., "Plasma lipid peroxidation in sporadic Parkinson's disease. Role of the L-dopa," Journal of Neurological Sciences, vol. 240, pp. 31-36, 2006. 


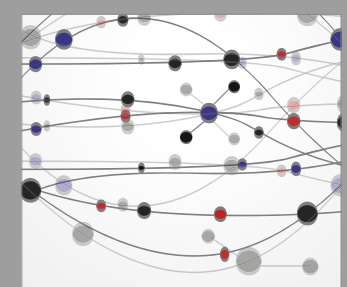

The Scientific World Journal
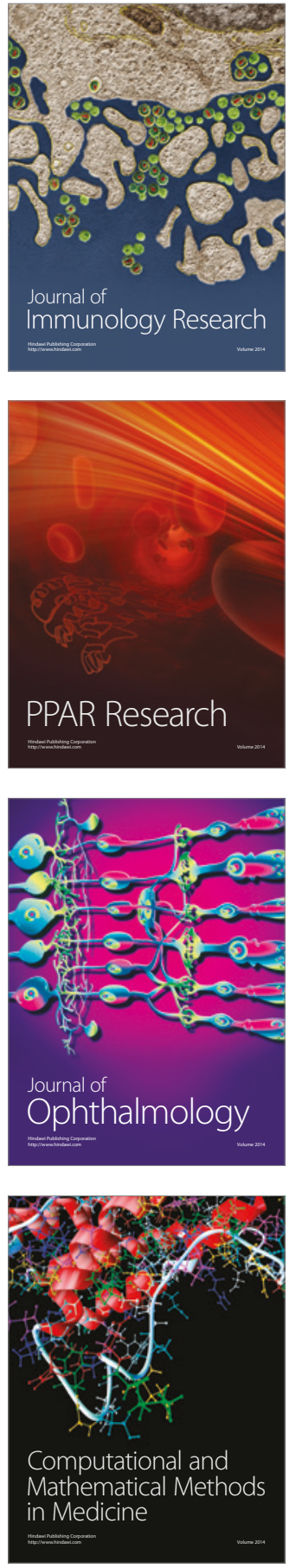

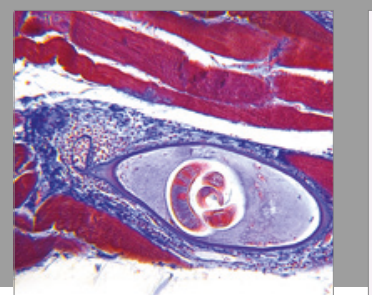

Gastroenterology Research and Practice
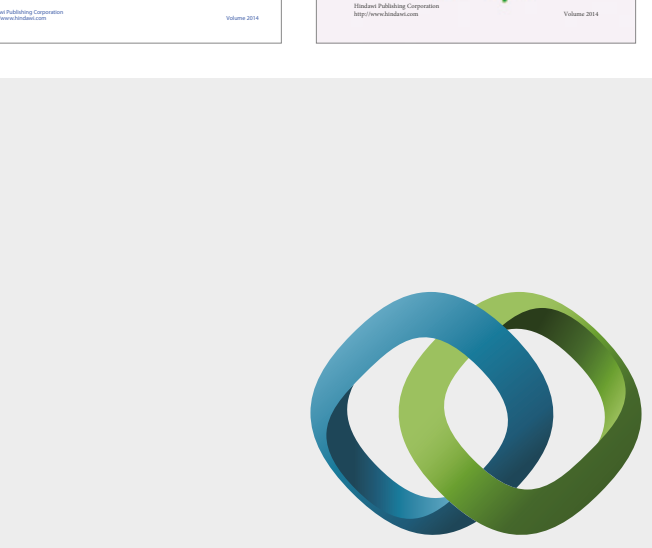

\section{Hindawi}

Submit your manuscripts at

https://www.hindawi.com
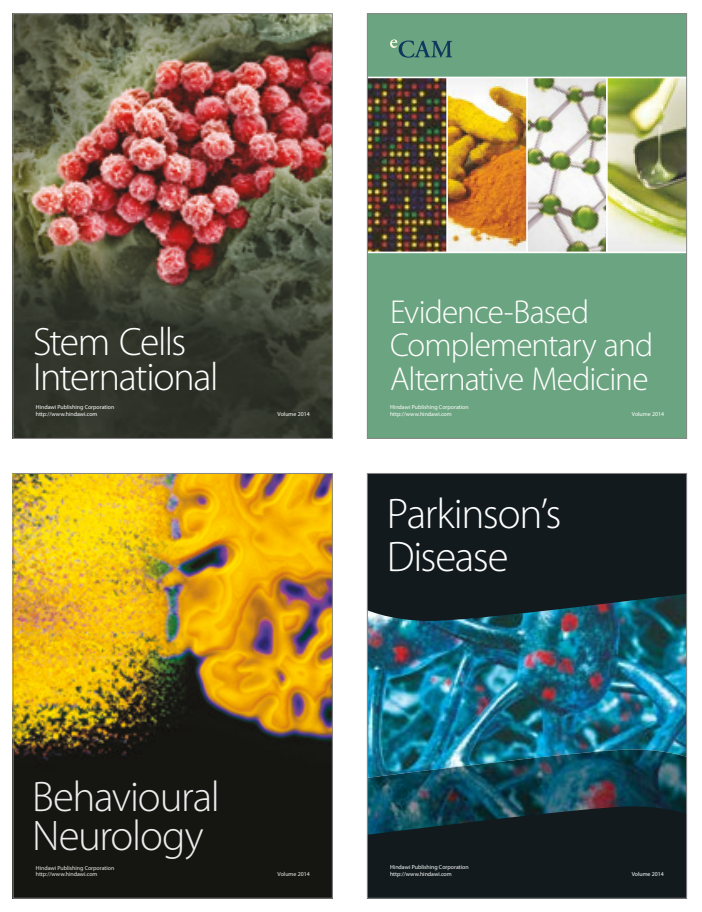
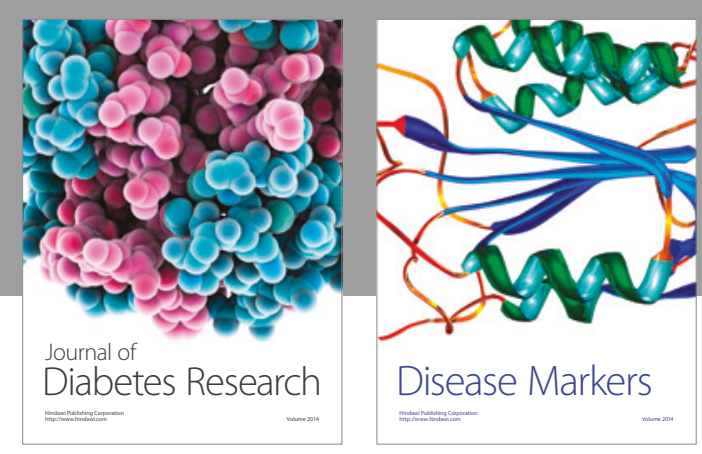

Disease Markers
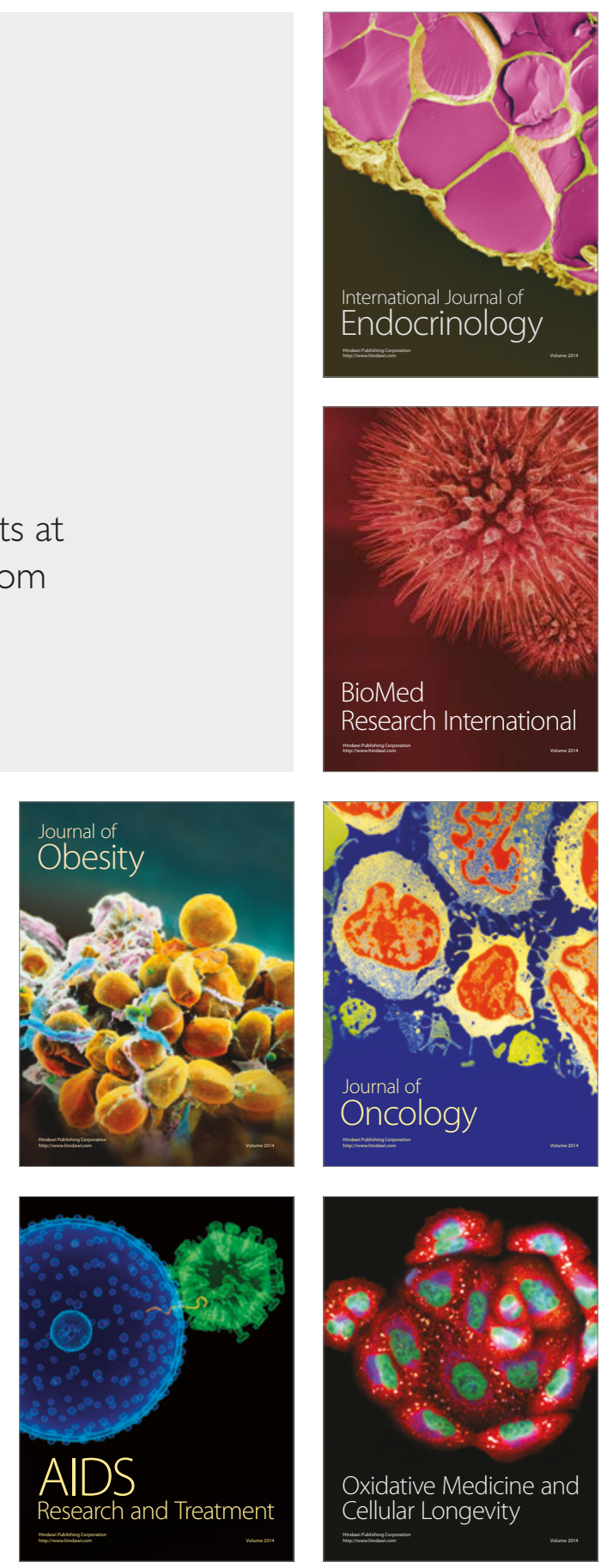